\title{
Computerized Tomography-Based Morphometric Analysis of Cervical Spinal Canal in Central Indian Population
}

\author{
Ambuj Kumar ${ }^{1}$ Subhash Sahu ${ }^{2}$ Shivank Sethi ${ }^{1}$ Shailendra Ratre ${ }^{1}$ Vijay Parihar ${ }^{1}$ Narayan Swamy ${ }^{1}$ \\ Yad Ram Yadav ${ }^{1}$ \\ ${ }^{1}$ Department of Neurosurgery, NSCB Medical College, Jabalpur, \\ Madhya Pradesh, India \\ 2Department of Plastic Surgery, Ramkrishna Care Hospital, Raipur, \\ Address for correspondence Vijay Parihar, MCh, Department \\ of Neurosurgery, NSCB Medical College, Jabalpur 482003, \\ Madhya Pradesh, India (e-mail: drvijayparihar@gmail.com).
} Chhattisgarh, India

J Neurosci Rural Pract 2020;11:274-277

\begin{abstract}
Objective Normal cervical spine canal morphometry is critical for understanding the pathology of certain diseases and for proper preoperative planning. Computerized tomography (CT) scan can replace older conventional radiography techniques by providing more accurate morphometric measurements. This study was aimed to find out various dimensions of the cervical spinal canal of central Indian population.

Materials and Methods A prospective study was conducted including 100 consecutive cervical spine CT scan of asymptomatic adult subjects. The anteroposterior sagittal canal diameter (SCD), transverse canal diameter (TCD), canal surface area (CSA), and Pavlov-Torg Ratio (PTR) from C2 to C7 were calculated.

Statistical Analysis Data were entered in Microsoft Excel Sheet 2007 and statistical analysis was performed by IBM SPSS statistics 2.0 version. $p$-Value $<0.05$ was considered as significant.

Results Age ranged from 18 years to 77 years with mean age 39.5 years. There was no significant difference in all the dimensions $(S C D, T C D, C S A)$ in male and female except at C2 level, where SCD, TCD, and CSA were significant larger in male. The mean SCD, TCD, and CSA is largest at C2 level $(14.4 \pm 1.63 \mathrm{~mm}, 21.57 \pm 1.59 \mathrm{~mm}$,

Keywords

- canal diameter

- cervical canal stenosis

- cervical spinal canal

- morphometry and $156.20 \pm 24.98 \mathrm{~mm}^{2}$, respectively) and smallest at C4 level $(12.77 \pm 1.48 \mathrm{~mm}$, $20.37 \pm 1.72 \mathrm{~mm}$, and $130.42 \pm 21.20 \mathrm{~mm}^{2}$ ). PTR showed very little variation.

Conclusion Normal values of cervical spinal canal could serve as a future reference. $\mathrm{CT}$ scan provides more accurate measurement. More studies are needed as there could be variations in dimensions in different regions in India.
\end{abstract}

\section{Introduction}

Cervical cord forms an integral anatomical and neurological part of spinal cord. The degenerative and traumatic pathologies affecting this region are manifold in character that can lead to severe neurological ailments and even mortality. Compromise in canal diameter is pivotal while managing the pathologies in this region. Hence, an insight of the normal cervical spine canal morphometry and its normal reference value are essential. Antecedent studies

DOI https://doi.org/

10.1055/s-0040-1703962

ISSN 0976-3147. for factual measurement of cervical spinal canal, in which plain X-ray was used, were deficient in congeniality due to magnification discrepancies. ${ }^{1-5}$ Computerized tomography (CT)-based studies comprehended various parameters such as pedicle measurements, foraminal dimensions, vertebral body width, and lateral mass dimensions. ${ }^{6,7}$ Nonetheless, there are only a very few studies pinpointing singularly on spinal canal diameter and these studies exhibit regional and ethnic diversification in cervical spinal canal morphometry. ${ }^{8-10}$ 
The aim of current study was to survey morphometric details of the cervical spinal canal on CT scan in central India. Our data could be a pragmatic tool for preoperative planning and postoperative follow-up of patients with cervical canal stenosis.

\section{Material and Methods}

This study was conducted in department of Neurosurgery, NSCB Medical College Hospital, Jabalpur and its affiliated CT scan center during the period from May 2018 to April 2019. Asymptomatic adult subjects of both sex and age equal to or above 18 years were included in the study. Exclusion criteria were age less than 18 years, history of any spinal trauma, surgery or pathology, history of significant neck pain, and evidence of congenital anomalies involving cervical spine. After prior approval from ethical committee, all subjects underwent CT cervical spine in a 16-row bright speed CT scan (GE healthcare) machine. CT scans were done in supine with neutral neck position. At all vertebral levels (C2-C7), anteroposterior(mid-sagittal) canal diameter (SCD) and transverse canal diameter (TCD) were measured. With the help of imaging software, canal surface area (CSA) was calculated. Pavlov-Torg ratio (PTR) was also calculated for each vertebral level as described by Pavlov et al ( - Fig. 1).

Data were entered in Microsoft Excel Sheet 2007 and statistical analysis was performed by IBM SPSS statistics 2.0 version. $p$-Value $<0.05$ was considered as significant.

\section{Results}

Mid-sagittal anteroposterior canal diameter (SCD), TCD, CSA, and PTR at C2 toC7 levels were measured in 100 asymptomatic adult subjects. Mean age of study population was 39.5 years (range: 18-77 years). There were 53 male and 47 female subjects with mean weight and height of $54.65( \pm 13.6) \mathrm{kg}$ and $155.55( \pm 10) \mathrm{cm}$, respectively (- Table 1).

The mean SCD, TCD, CSA, and PTR from C2 to C7 in all 100 subjects are shown in - Table 2 . There is no significant difference in all the dimensions (SCD, TCD, CSA) in male and female except at C2 level, where SCD, TCD, and CSA were significant larger in male. (SCD: $14.80 \pm 1.67 \mathrm{~mm}$ vs. $13.99 \pm 1.47 \mathrm{~mm}$, $p$ <0.0003; TCD: $21.9 \pm 1.7 \mathrm{~mm}$ vs. $21.1 \pm 1.29 \mathrm{~mm}, p<0.009$; CSA: $163.2 \pm 26.7 \mathrm{~mm}^{2}$ vs. $\left.148.2 \pm 20.7 \mathrm{~mm}^{2}, p<0.002\right)$. The mean SCD, TCD, and CSA was largest at C2 level $(14.4 \pm 1.63 \mathrm{~mm}$, $21.57 \pm 1.59 \mathrm{~mm}$, and $156.20 \pm 24.98 \mathrm{~mm}^{2}$, respectively) and smallest at C4 level $(12.77 \pm 1.48 \mathrm{~mm}, 20.37 \pm 1.72 \mathrm{~mm}$, and $130.42 \pm 21.20 \mathrm{~mm}^{2}$ ). PTR was highest at C2 level. Subaxial cervical spine showed very little variation in PTR.

\section{Discussion}

Pathologies of the cervical spine are prevalent in all parts of the world. Unabridged anatomical know-how of this region is of paramount importance prior to handling them. Morphological divergence of cervical spinal canal among different races, religions, body habitus, gender, and geographical areas is well acknowledged. Although there are many studies
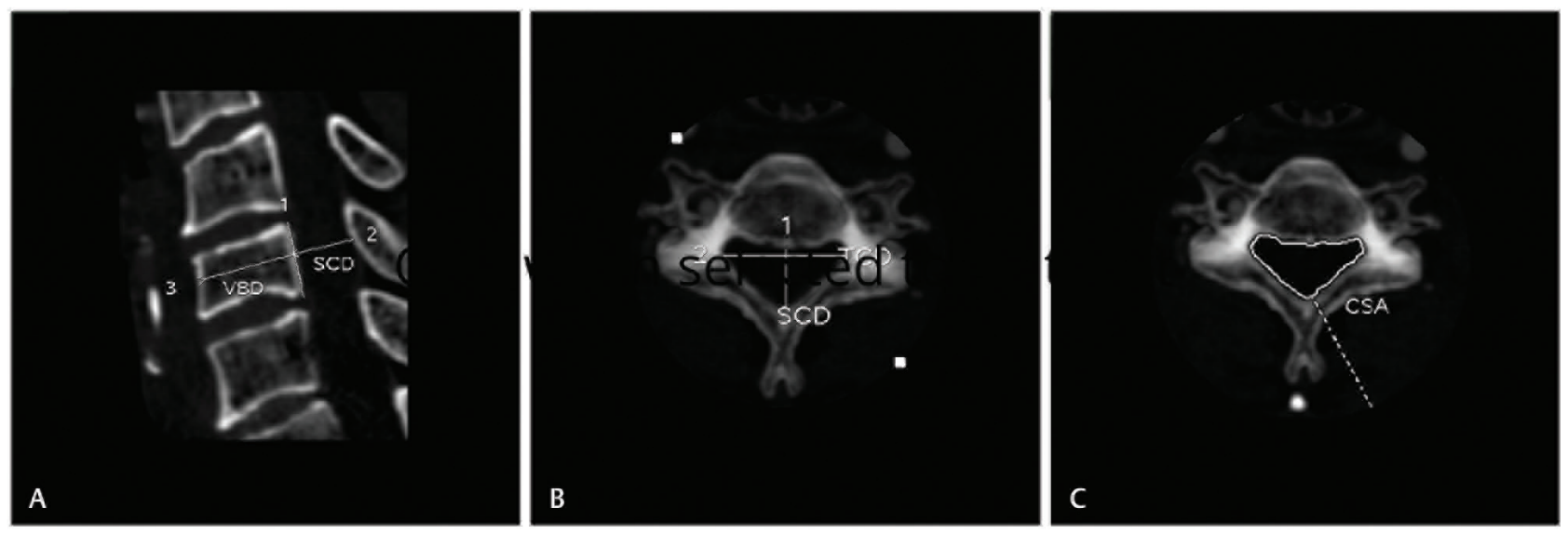

Fig. 1 (A) Sagittal canal diameter (SCD) at mid-vertebral level and vertebral body diameter (VBD) were measured on the mid-sagittal images. (B) Transverse canal diameter and (C) Canal surface area (CSA) were measured on the axial images from C2 to C7.

Table 1 Patients' characteristics (age in y, weight in kg, and height in cm)

\begin{tabular}{|l|l|l|l|}
\hline Patients' characteristics & Total (100) & Male $(\boldsymbol{n}=\mathbf{5 3})$ & Female $(\boldsymbol{n}=\mathbf{4 7})$ \\
\hline Age \pm SD (range) & $39.53 \pm 16.8$ & $42.22 \pm 18.2$ & $36.5 \pm 14.54$ \\
& $(18-77)$ & $(18-77)$ & $(18-75)$ \\
\hline Height \pm SD (range) & $155.55 \pm 10$ & $159.24 \pm 10$ & $151.30 \pm 8.25$ \\
& $(122-176)$ & $(122-176)$ & $(122-168)$ \\
\hline Weight \pm SD (range) & $54.65 \pm 13.6$ & $56.77 \pm 14$ & $52.21 \pm 12.78$ \\
& $(38-90)$ & $(36-90)$ & $(36-90)$ \\
\hline
\end{tabular}

Abbreviation: SD, standard deviation. 


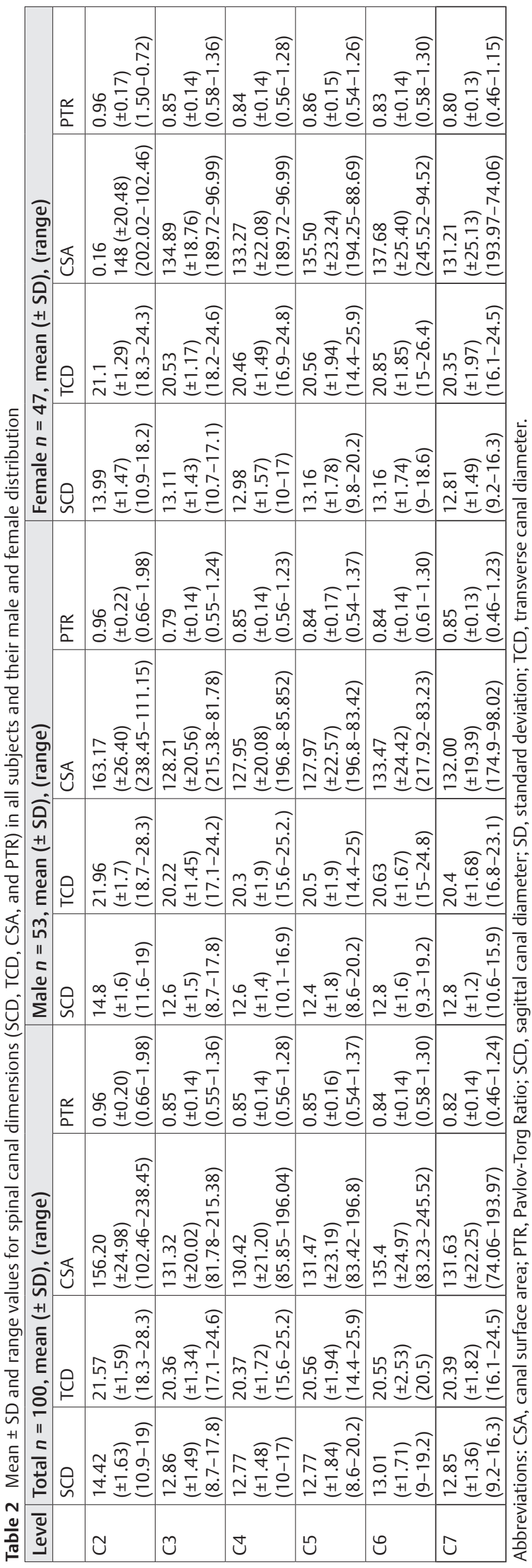

describing normal dimensions of the cervical spinal canal in different geographical regions in India, there is a paucity of CT scan-based studies. CT yields more authentic dimension of bony spinal canal in comparison to X-ray. Recent advances in CT modalities have made the anatomical measurements in the human body more feasible and scrupulous. ${ }^{9}$

Our data will be a propitious tool for preoperative planning and postoperative follow-up of patients of cervical canal stenosis.

\section{Canal Dimensions}

In present study, average SCD of cervical spine was $13.11 \pm 0.59 \mathrm{~mm}$ and it gradually declined from C2 to C4. At C4 to C5 and C5 to C6 level, SCD increased followed by decrease in sagittal diameter at $\mathrm{C} 6$ to $\mathrm{C7}$. The SCD was smallest at $\mathrm{C} 4$ level for both males and females. These results reciprocated with the results by other authors such as Evangelopoulos et $\mathrm{al}^{8}$ in their CT-based morphometric analysis of cervical spine and Song et $\mathrm{al}^{11}$ in their study on spinal stenosis and neurological outcome in traumatic cervical spine injury. As per the available literature, mid-SCD has been found to be larger in European and American population in comparison to Asian population suggesting a possible ethnic difference. ${ }^{9}$ Lee et al found average sagittal cervical canal diameter (C3C7) as $14.1 \pm 1.6 \mathrm{~mm}$ in their studies. Measurements were done on cadaver specimens and SCD was found cardinally larger in males in comparison to females. ${ }^{12}$ Morishita et al, in their study based on magnetic resonance imaging (MRI), reported $13.73 \pm 1.37 \mathrm{~mm}$ as average SCD from C3 to C7..$^{13}$ Likewise, Tierney et al reported average SCD $13.28 \pm 1.47 \mathrm{~mm}$ based on MRI. MRI is precise in defining soft tissue details such as space for cord; however, bony dimensions are better deciphered by CT. ${ }^{14}$ While study based on plain radiograph shows higher range of diameter and significant difference between male and female, these variations could be due to technical limitation with plain radiograph. ${ }^{15}$

In literature, significant variation in spinal canal transverse diameter between different races had been reported. Indian population has relatively small canal size as per the literature. ${ }^{16,17}$ Current study shows mean TCD of cervical spinal canal as $20.63 \pm 0.43 \mathrm{~mm}$. In our study TCD does not show much variation except at C2 level where it is large. Most studies reveal C3 and C5 as level with minimum and maximum mean TCD, respectively. In these studies, healthy asymptomatic individuals as well as patients with myelopathy or radiculopathy were included, but no significant difference in TD among these subgroups was noted. ${ }^{9}$

The average cross-sectional CSA in our study was $136.07 \pm$ $9.14 \mathrm{~mm}^{2}$ with minimum CSA at C4 level. Though various studies describe narrowing of spinal canal at C3 level, the exact significance of variation in spinal canal cross-sectional surface area is not known. ${ }^{18}$ Also when comparison was made between the control and the spinal canal injured group on the basis of cross-sectional area of the spinal canal, the results were equivocal. ${ }^{19}$ Consequently, nowadays by using MRI, ratio of spinal canal to cord transverse area is used to define the stenosis. ${ }^{18}$ 
PTR was proposed in 1987 as a radiographic tool to measure spinal canal stenosis. ${ }^{5}$ Significant spinal stenosis and an increased risk for neurologic injury are considered when the ratio is less than 0.80 and 0.70 , respectively. ${ }^{5,19,20}$ In comparison to spinal-canal diameter, the PTR is a worthier indicator of spinal stenosis; however, it is highly variable between different genders and races. ${ }^{14,21}$ Herzog et al evaluated PTR on the basis of plain radiographs, and reported a high sensitivity but a poor positive predictive value. ${ }^{22}$ Contrarily, CT scan and MRI perform accurate measurements of the anatomical structures of the cervical spine, thus avoiding technical errors that could lead to false calculations. ${ }^{18}$ The average PTR in our study was $0.86 \pm 0.05$ with no significant gender discrepancy.

\section{Strengths and Limitations}

The robustness of current study is a substantial sample size. Also, morphometric analysis was based on CT scan that is a more meticulous tool than conventional radiograph. In CT scan, we had calculated the accurate transverse diameter and surface area that are equivalently imperative in predicting the spinal stenosis. This study does have some limitations. First is that, pediatric age group, which is the age group for anomalies of this region, has not been studied. Also, we calculated dimensions at mid-vertebral level, while the degenerative pathology commonly affects the interbody level.

\section{Conclusion}

In conclusion, $\mathrm{CT}$ scan provides more accurate morphometric measurement of cervical spine in normal asymptomatic population as compared with plain radiographs. These morphometric dimensions show ethnic, racial, and geographical variations and hence normal reference value of population of particular region is important. These reference values can be useful aid in preoperative evaluation, surgical planning, and postoperative follow-up of cervical stenosis patients. Comparison with cervical canal stenosis patient's data will be helpful for further anatomical and pathological correlation. Study on pediatric group is also required for assessment of congenital anomalies.

\section{Conflict of Interest}

None declared.

\section{Reference}

1 Hashimoto I, Tak YK. The true sagittal diameter of the cervical spinal canal and its diagnostic significance in cervical myelopathy. J Neurosurg 1977;47(6):912-916

2 Ishikawa M, Matsumoto M, Fujimura Y, Chiba K, Toyama Y. Changes of cervical spinal cord and cervical spinal canal with age in asymptomatic subjects. Spinal Cord 2003;41(3):159-163

3 Tatarek NE. Variation in the human cervical neural canal. Spine J 2005;5(6):623-631

4 Remes VM, Heinänen MT, Kinnunen JS, Marttinen EJ. Reference values for radiological evaluation of cervical vertebral body shape and spinal canal. Pediatr Radiol 2000;30(3):190-195
5 Pavlov H, Torg JS, Robie B, Jahre C. Cervical spinal stenosis: determination with vertebral body ratio method. Radiology 1987;164(3):771-775

6 Kwon BK, Song F, Morrison WB, et al. Morphologic evaluation of cervical spine anatomy with computed tomography: anterior cervical plate fixation considerations. J Spinal Disord Tech 2004;17(2):102-107

7 Abdullah KG, Steinmetz MP, Mroz TE. Morphometric and volumetric analysis of the lateral masses of the lower cervical spine. Spine 2009;34(14):1476-1479

8 Evangelopoulos D, Kontovazenitis P, Kouris S, et al. Computerized tomographic morphometric analysis of the cervical spine. Open Orthop J 2012;6:250-254

9 Chazono M, Tanaka T, Kumagae Y, Sai T, Marumo K. Ethnic differences in pedicle and bony spinal canal dimensions calculated from computed tomography of the cervical spine: a review of the English-language literature. Eur Spine J 2012; 21(8):1451-1458

10 Morphometry of the spinal canal at cervical region in asymptomatic military young men. http://www.scielo.br/scielo. php?script=sci_arttext $\&$ pid=S1413-78522002000400006. Accessed July 6, 2019

11 Song K-J, Choi B-W, Kim S-J, Kim G-H, Kim Y-S, Song J-H. The relationship between spinal stenosis and neurological outcome in traumatic cervical spine injury: an analysis using Pavlov's ratio, spinal cord area, and spinal canal area. Clin Orthop Surg 2009;(11):11-18

12 Lee MJ, Cassinelli EH, Riew KD. Prevalence of cervical spine stenosis. Anatomic study in cadavers. J Bone Joint Surg Am 2007;89(2):376-380

13 Morishita Y, Naito M, Hymanson H, Miyazaki M, Wu G, Wang JC. The relationship between the cervical spinal canal diameter and the pathological changes in the cervical spine. Eur Spine J 2009;18(6):877-883

14 Tierney RT, Maldjian C, Mattacola CG, Straub SJ, Sitler MR. Cervical spine stenosis measures in normal subjects. J Athl Train 2002;37(2):190-193

15 Kathole MA, Joshi RA, Herekar NG, Jadhav SS. Dimensions of Cervical Spinal Canal and Vertebrae and their Relevance in Clinical Practice. Int J Recent Trends Sci Tech. 2012;3:54-58

16 Amonoo-Kuofi HS, Patel PJ, Fatani JA. Transverse diameter of the lumbar spinal canal in normal adult Saudis. Acta Anat (Basel) 1990;137(2):124-128

17 Devi R, Rajagopalan N. Dimensions of the lumbar vertebral canal. Indian J Orthop 2003;37(3):13

18 Solanki GA, Lo WB, Hendriksz CJ. MRI morphometric characterisation of the paediatric cervical spine and spinal cord in children with MPS IVA (Morquio-Brailsford syndrome). J Inherit Metab Dis 2013;36(2):329-337

19 Matsuura P, Waters RL, Adkins RH, Rothman S, Gurbani N, Sie I. Comparison of computerized tomography parameters of the cervical spine in normal control subjects and spinal cordinjured patients. J Bone Joint Surg Am 1989;71(2):183-188

20 Castro FP Jr, Ricciardi J, Brunet ME, Busch MT, Whitecloud TS II. Stingers, the Torg ratio, and the cervical spine. Am J Sports Med 1997;25(5):603-608

21 Blackley HR, Plank LD, Robertson PA. Determining the sagittal dimensions of the canal of the cervical spine. The reliability of ratios of anatomical measurements. J Bone Joint Surg Br 1999;81(1):110-112

22 Normal cervical spine morphometry and cervical spinal stenosis in asymptomatic professional football players. Plain film radiography, multiplanar c... - - NCBI. https://www.ncbi. nlm.nih.gov/pubmed/1862411. Accessed July 6, 2019 